\title{
Being Optimally Aroused Matters: Effects of a Weak Stress Manipulation on Children's Executive Functions Are Moderated by Temperament and Age
}

\author{
Regula Neuenschwander ${ }^{1,2}$, Claudia M. Roebers ${ }^{2}$ \& Clancy Blair ${ }^{1}$ \\ ${ }^{1}$ Steinhardt School of Culture, Education, and Human Development, New York University, New York, USA \\ ${ }^{2}$ Department of Developmental Psychology, University of Bern, Bern, Switzerland \\ Correspondence: Regula Neuenschwander, 196 Mercer St, 8th floor, New York, NY 10012, USA. Tel: 1- \\ 212-992-6874. E-mail: rn872@nyu.edu
}

Received: February 25, 2014

doi:10.5539/jedp.v4n1p194

\begin{abstract}
We tested a core assumption of the bidirectional model of executive function (EF) (Blair \& Ursache, 2011) indicating that EF is dependent on arousal. From a bottom-up perspective the performance on EF tasks is assumed to be curvilinearly related to arousal, with very high or low levels of arousal impairing EF. $N=1074$ and 6-year-olds' performance on EF tasks was explored as a function of a weak stress manipulation aiming to raise children's emotional arousal. EF (Stroop, Flanker, Go/no-go, and Backwards Color Recall) was assessed and stress was induced in half of the children by imposing a mild social-evaluative threat. Furthermore, children's temperament was assessed as a potential moderator. We found that stress effects on children's EF performance were moderated by age and temperament: 4-year-olds with high Inhibitory Control and high Attentional Focusing were negatively affected by the stressor. However, it is unclear whether these effects were mediated by self-reported arousal. Our findings disconfirmed the hypotheses that adverse effects of the stressor are particularly high in children high on emotional reactivity aspects of temperament and low on self-regulatory aspects of temperament. Further, 6-year-olds did not show any stress effects. Results will be discussed within the framework of the Yerkes-Dodson law and with regard to stress manipulations in children.
\end{abstract}

Keywords: executive functions, stress manipulation, temperament, arousal, children around transition to school

\section{Introduction}

In many ways, successful adaptation to early school contexts requires an effective balance between emotion and cognition (Blair, 2002; Raver, 2002). Maintaining an appropriate level of emotional arousal facilitates rather than impedes the application of higher order cognitive functions like executive functions (EFs) to tasks important for learning (Blair \& Dennis, 2010). It is well established that a high level of emotional arousal reduces the ability to flexibly control attention and impairs EF (e.g., Alexander, Hillier, Smith, Tivarus, \& Beversdorf, 2007; Lupien, Gillin, \& Hauger, 1999). However, at present little is known about the specific relationship between emotional arousal and EF in children around the transition to school. This knowledge is crucial in the context of early childhood education as it serves to inform educators about the extent to which particular types of experiences and educational curricula lead to optimal levels of arousal and engagement (Blair \& Ursache, 2011). In the present study, we explored the relation between age, emotional arousal, and performance on EF tasks in a sample of 4- and 6-year-olds.

\subsection{Bidirectional Model of EF}

The bidirectional model of EF (Blair \& Ursache, 2011) emphasizes the notion that EF can be conceptualized as an aspect of self-regulation that is important for but also dependent on the regulation of emotion and attention. Generally, EF represent a complex and interrelated set of higher order cognitive processes, including the maintenance and manipulation of relevant information (updating), inhibition of predominant responses (inhibition), and mental set shifting (shifting; Miyake, Friedman, Emerson, Witzki, \& Howerter, 2000). EF is often described as serving a critical higher-level or top-down role in behavior regulation like directing attention and organizing cognitive resources (Miller \& Cohen, 2001) or regulating emotions (Ochsner \& Gross, 2005). The bidirectional model of EF emphasizes that while EF can serve a top-down role in behavior regulation, from 
a bottom-up perspective EF can also be characterized as dependent on reactivity and regulation in lower-order, more automatic emotion, attention, and stress response systems (Blair \& Dennis, 2010; J. R. Gray, 2004). That is, in contexts that lead to particularly high levels of attentional focus and emotion and stress arousal, EF is impaired (e.g., Alexander et al., 2007; Lupien et al., 1999). This specific association reflects to some extent the fact that stress hormone levels (e.g., cortisol) modulate synaptic activity in the neural circuitry of prefrontal cortex (PFC), the brain region that subserves EF. Interestingly, recent research in neuroscience (for an overview see, Arnsten, 2009; Lupien, Maheu, Tu, Fiocco, \& Schramek, 2007) has shown that the functional relation between arousal and performance on complex cognitive tasks described by Yerkes and Dodson (1908) is mirrored in neural activity at the biological level. This functional relation can be thus described as a curvilinear, inverted U-shape (Blair \& Ursache, 2011; Yerkes \& Dodson, 1908).

\subsection{Yerkes-Dodson Law}

The Yerkes-Dodson law originally indicates that the stimulus strength (cf. level of arousal) influences the speed of habit formation (cf. efficacy of learning or level of performance) for tasks varying in discrimination difficulties. Whereas performance on simple cognitive tasks is linearly and positively related to arousal, performance on a complex cognitive task increases with physiological arousal, but only up to a point. When levels of arousal become too high, performance decreases. The upward part of the inverted $U$ can be thought of as the energizing effect of arousal whereas the downward part is characterized by deteriorating effects of arousal on higher cognitive functions like executive attention, problem-solving, or EF. Thus, just as emotional processes at very high levels can disrupt EF, emotion at moderate levels facilitates EF. This inverted U-shape curve has been shown in research with animals (Arnsten \& Goldman-Rakic, 1998), but has not been studied extensively in humans due to methodological challenges (cf. Arnsten, 2009). In our study, a weak stress manipulation was used to manipulate (i.e., raise) children's arousal in order to explore its effects on children's EF performance.

\subsection{Inter-Individual Differences in Arousal}

Given that performance on EF tasks is highest at moderate levels of arousal our goal was to investigate the degree to which two variables - children's age and temperament - contribute to inter-individual differences in arousal. From a developmental perspective, children's age is assumed to be strongly associated with the level of difficulty (i.e., subjective probability of success, cf. Atkinson, 1957). Based on research showing that rapid improvements occur during the preschool and early school years on EF tasks (for an overview see, Best \& Miller, 2010), it can be concluded that a given EF task is more difficult and hence more challenging for a younger compared to an older child. An older child will perform better on that same task (i.e., will have a higher subjective probability of success) and will hence most likely experience it as less difficult. We assume that children's age (i.e., the subjective level of difficulty) is closely related to baseline levels of arousal.

Temperamental characteristics may not only moderate the process if a situation is perceived as stressful (Strelau, 1995) but even more basically account for inter-individual differences in arousal and regulation thereof (J. A. Gray, 1982; Rothbart et al., 2001). Temperament is thereby defined as individual differences in emotional, motor, and attentional reactivity as well as self-regulation (Rothbart \& Bates, 2006). In the presence of a stressor children may experience it and react to it differently depending on inter-individual differences in self-regulatory (e.g., Inhibitory Control, Attentional Focusing) and emotional reactivity aspects (e.g., Fear, Behavioral Inhibition) of temperament. Fear is assumed to be of particular interest within the context of a stress manipulation because Fear is defined as the amount of "negative affectivity, including unease, worry, or nervousness, which is related to anticipated pain or distress and/ or potentially threatening situations" (Rothbart et al., 2001, p. 1406). Similarly, temperament facets based on biological theories of temperament (Gray, 1982) include the behavioral approach system (BAS) and the behavioral inhibition system (BIS). When activated by cues of threat or novelty, BIS produces behavioral inhibition or withdrawal (i.e., high arousal). Further, experiencing stress may also depend upon the development of capacities which help to modulate emotional reactivity, such as dimensions of effortful control (e.g., Attentional Focusing, Inhibitory Control). In presence of an acute stressor, children high in Attentional Focusing are assumed to be better at focusing their attention on task relevant features and not being distracted by the automatic response associated with heightened emotion. Similarly, children with high Inhibitory Control are assumed to be better at inhibiting the automatic response associated with heightened emotion. In conjunction with the notion that arousal is curvilinearly related to performance (Yerkes \& Dodson, 1908) we predicted that the performance of older and younger children with different temperamental characteristics should be differentially affected by manipulations of arousal. 


\subsection{Stress Manipulation}

Meta-analysis has indicated that stressors that are uncontrollable or characterized by a social-evaluative threat elicit the most pronounced cortisol changes (i.e., stress responses) with the longest recovery times in adults (Dickerson \& Kemeny, 2004), but less is known about effective stressor paradigms in children. In an overview of stressor paradigms applied in developmental studies Gunnar, Talge, and Herrera (2009) concluded that the availability of coping resources and the extent to which the task threatens the social self (in older children) seem to be at least two factors that are critical in determining whether a stressor paradigm is successful (e.g., public speaking paradigms like the Trier Social Stress Test for Children, Buske-Kirschbaum et al., 2003). Following this research, we chose to implement a stress manipulation by imposing a social-evaluative threat on children (i.e., children in the experimental group were told that the tasks are going to be very difficult and that all the other children did an excellent job). As we were concerned about generalizability of our results to children's everyday life (i.e., high external validity) we wanted the experimental stressor to look like a situation that is likely to occur in a child's everyday life. Our procedure may be therefore considered as a weak social-evaluative threat. Similar stress manipulations have been implemented in research on children's test anxiety (high situational stress was induced by telling 10-year-olds that their results would be recorded in their school report books if they failed the test, $\mathrm{Ng} \&$ Lee, 2010). By means of self-reported feelings of nervousness and fear we wanted to explore if the present stress manipulation affected the cognitive, conscious component of the arousal children experience in such situations (cf. Ng \& Lee, 2010).

\subsection{The Present Study}

Our design included two age groups of children around the transition to school (4- and 6-year-olds), temperamental factors, and a weak stress manipulation to assess their joint effects on EF task performance. Our specific research questions and hypotheses are as follows.

First, does the present stress manipulation affect children's performance on EF tasks? Given prior evidence of stressor paradigms in 4- to 8-year-olds (Buske-Kirschbaum et al., 2003; Gunnar et al., 2009) we hypothesized that our stress manipulation would be effective because it included a social-evaluative threat. Given that the PFC disengages at high levels of arousal and neural processes revert to more automatic and reflexive responses (Blair, 2002), we expected that children who were exposed to the stressor would have fewer correct responses on the EF tasks than children who were not exposed to the stressor.

Second, are present stress effects age-dependent? Given that the range of optimal arousal depends on the level of difficulty of the tasks (Atkinson, 1957; Best \& Miller, 2010) the present study included two age groups to detect age-specific stress effects. We hypothesized that the younger cohort would be more challenged than the older cohort by the applied EF tasks and therefore their baseline arousal would be at a higher level compared to the baseline arousal of the older cohort. Consequentially, stress effects would be more pronounced in the younger cohort.

Third, which children are specifically at risk for showing poor EF performance under the stress condition? As temperamental characteristics may not only moderate the process if a situation is appraised as threating and perceived as stressful (Strelau, 1995) but may also account for inter-individual differences in emotional arousal and regulation thereof (Rothbart et al., 2001), we hypothesized that children would be differentially affected by the stressor based on their temperament. More precisely, we assumed that children high on self-regulatory aspects of temperament (high Inhibitory Control and high Attentional Focusing) would be better at regulating the heightened emotional arousal they experienced from the stress manipulation, and therefore continue to perform well on the EF tasks. However, children high on emotional reactivity aspects of temperament were hypothesized to react more strongly to the stressor. Consequently, we hypothesized that children high in Fear experiencing more negative affect in the presence of the stressor, would be more aroused and therefore be at higher risk for inferior performance on the EF tasks. Similarly, children with high BIS would react stronger to the stress manipulation and would thus be more aroused and at higher risk for inferior performance on the EF tasks.

Finally, what are the mechanisms through which these effects occur? On a psychological level, does the arousal a child consciously experiences during the test session account for the stress effects? Following research on test anxiety ( $\mathrm{Ng} \&$ Lee, 2010), we hypothesized that children in the stress condition would report to be more nervous than children in the control group (i.e., manipulation check). 


\section{Method}

\subsection{Participants}

One hundred and fifteen children from public kindergartens and elementary schools in Switzerland participated in the current study. For the present study only children whose parents completed the questionnaire $(N=107)$ were included as these variables were of substantive interest to our research questions (i.e., eight children were lost due to incomplete data). Two groups of children were recruited: 6-year-olds and 4-year-olds, allowing us to examine age-dependent stress effects in children around the transition to school. Thus, the sample consisted of $n$ $=34$-year-old children who attended their first year of kindergarten $(M=4.9$ years, range $=4.3$ to $5.11 ; 47.1 \%$ girls) and $n=73$ 6-year-old children who attended first grade in elementary school ( $M=6.9$ years, range $=6.0$ to $7.7 ; 49.3 \%$ girls). Children were recruited from public kindergartens and elementary schools in different urban and rural regions of Switzerland. Parents and teachers gave their written informed consent. Although the home language background of $13.9 \%$ of the children was different than German, a proportion that is representative for the Swiss population, all participants were sufficiently fluent in the German language.

\subsection{Procedure}

Data was collected during the first semester of the school year (September to October 2012). All tests were administered in separate quiet rooms at the kindergarten or at the school by a trained experimenter. Each child was seen twice between 8:00 a.m. and 12:00 p.m. with a session lasting approximately $40 \mathrm{~min}$. Thus, half of the tasks were administered in the first session, and half were administered in the second session. Fixed order of task administration was used, where tests with different presentation and response format were alternated to yield not only a well-paced assessment experience for the child but also to combat performance variation due to fatigue. Computerized tasks were all run using E-Prime 2.0 (Psychological Software Tools, Pittsburgh, PA). After the second session, children were thanked for their cooperation and received a small gift. Parents filled out the questionnaires at home and returned them via teachers. Parental response rate was high (93\%).

\subsubsection{Stress Manipulation}

Children were randomly assigned to either the control or the experimental group. Stress was induced in half of the children by imposing a mild social-evaluative threat. At the beginning of each session children in the experimental group were told: "Today we are going to do some games and tasks. Some of them will be very difficult and I want you to try very hard. All the other children did an excellent job and now we will see how good you are." Whereas children in the control group were told: "Today we are going to do some games and tasks. Some of them will be difficult and some of them will be easy. I want you to try very hard."

\subsection{Measures}

\subsubsection{EF}

EF was assessed with the four tasks described below. Selected tasks were assumed to emphasize either inhibitory components of EFs (Flanker, Go/no-go, Stroop) or the updating EF component (Backwards Color Recall). These tasks were either specifically developed for preschool and early school children and/ or have been shown to be developmentally-sensitive measures within the studied age range (Röthlisberger, Neuenschwander, Michel, \& Roebers, 2010).

Flanker. In the Flanker task (child-friendly adaption of the Flanker task by Eriksen \& Eriksen, 1974; Roebers, Schmid, \& Roderer, 2010), the child was instructed to feed the hungry fish in the center by pressing the button on the side where the fish's mouth was pointing as fast and accurately as possible while ignoring the flanker stimuli. If the fish in the center of the screen thus pointed to the left side, the child had to press the left response button with the left hand. By contrast, if the centrically presented fish was oriented to the right side, the child had to press the response button on the right side with his right hand. In the congruent condition, flanker stimuli consisted of fish pointing in the same direction; in the incongruent condition, flanker stimuli pointed in the opposite direction. First, a pure block consisting of 12 congruent trials was presented to the child. Then two blocks consisting of 24 block-randomized trials each were carried out. These blocks consisted each of $2 / 3$ congruent trials (16) and 1/3 incongruent trials (8). Each trial began with a crosshairs; then the stimulus array appeared for a maximum of $3,000 \mathrm{~ms}$ or until a response occurred, with the interval between response and onset of the next trial varying randomly between $800-1,400 \mathrm{~ms}$. At the end of each session children received feedback based on the accuracy of their responses, showing how well the fish had been fed. Accuracies and response latencies were recorded. Accuracies in the congruent and incongruent trials were the dependent variable because they were better distributed (i.e., in the sense of a normal distribution) than accuracies of incongruent trials only. 
Go/no-go. A preschool-appropriate Go/no-go task was designed guided by the extant preschool literature (Archibald \& Kerns, 1999; Cragg \& Nation, 2008; Wiebe, Sheffield, \& Espy, 2012). The task was framed as a fishing game. A background scene consisting of sky, water, and a fisherman in a boat holding a fishing net was constantly present on the screen. Children were instructed to catch the jellyfish by pressing a button whenever a jellyfish appeared on the screen. In contrast, children were told not to catch the starfish and thus not to press the button when a starfish appeared on the screen. Go and no-go stimuli were selected to share many features (i.e., animals with similar colors and size), but were nevertheless easily differentiated and familiar to preschool children, in order to facilitate their learning the task rule. First, to encourage the development of a prepotent response, a pure go block consisting of 16 go trials was presented to the child. Then two blocks consisting of 48 block-randomized trials each were carried out. These blocks consisted each of $75 \%$ go trials (36) and $25 \%$ no-go trials (12). On each trial the stimulus (jellyfish or starfish) appeared on the screen for $450 \mathrm{~ms}$, or until a response occurred, followed by a fixed interval of $2,300 \mathrm{~ms}$. At the end of each session children received a standardized feedback, showing jellyfish that were caught in the net. Accuracies and response latencies were recorded. Accuracies were computed separately for go and no-go trials, and mean response times were calculated for correct go trials. The proportion of hits (correct go trials) and false alarms (incorrect no-go trials) were used to calculate a discrimination index (hits minus false alarms). This discrimination index served as dependent variable, where higher values reflect better discrimination.

Backwards Color Recall. A preschool friendly task that is analogue to a backwards digit span task, the Backwards Color Recall task (Schmid, Zoelch, \& Roebers, 2008) was administered. Children were told to help a dwarf by looking for colored discs he had lost. Precisely, a sequence of sequentially displayed colored discs had to be recalled in reverse order. Thus, the relevant information (colors) did not only have to be remembered but was also required to be manipulated (recall in reverse order). Colored discs were presented on a computer screen for $1 \mathrm{~s}$ and only colors with monosyllabic (German) names were selected. There were three trials per span. The next span was only passed on to if two of the three trials were recalled correctly, though the current span was always completed. The dependent variable was the number of trials correctly recalled in the reverse order.

Stroop. An adapted version of the Fruit Stroop task used by Archibald and Kerns (1999) was applied. Different pages always displaying 25 items were presented to the child: The first page displayed 25 colored squares and children had to name the colors as quickly as possible. On the second page, four different fruits and vegetables in their original color were presented (congruent condition), followed by a third page displaying the same fruits and vegetables colored in black and white and children were asked to name the original colors. The fourth and final page showed the fruits and vegetables in incorrect colors and children were again asked to name the original color (incongruent condition). The dependent variable was the number of errors in the incongruent condition.

\subsubsection{Temperament}

Temperament was measured by two questionnaires through parent report.

$C B Q$. Children's temperament was rated on the CBQ (short form, German translation, Rothbart et al., 2001). The CBQ is a measure of child temperament appropriate for children between the ages of 3 and 7 years. Parents rated to what extent a particular behavior was true for their child on a 7-point Likert scale ranging from extremely true to extremely untrue. The short form consists in total of 94 items that are aggregated to 15 subscales. In the current study the following three subscales with six items each (showing satisfactory reliability in the present sample) were of particular interest: Inhibitory Control $(\alpha=.73)$, Attentional Focusing $(\alpha=.73)$, and Fear $(\alpha$ $=.73$ ). Sample items for Inhibitory Control are: My child is good at following instructions and My child can wait before entering into new activities if s/he is asked to; for Attentional Focusing: My child sometimes becomes absorbed in a picture book and looks at it for a long time and My child, when practicing an activity, has a hard time keeping her/his mind on it (reversed); for Fear: My child is afraid of loud noises and My child is rarely frightened by "monsters" seen on TV or at movies (reversed).

$B I S / B A S$. Parents also completed a version of the BIS/ BAS scales (Carver \& White, 1994) that were modified for parent report (cf. Blair, 2003; for German translation in an adult sample see Strobel, Beauducel, Debener, \& Brocke, 2001). The BIS/ BAS scales are a measure of approach withdrawal motivation aiming to capture sensitivity to appetitive and aversive stimuli. Parents rated statements about their child on a 7-point Likert scale ranging from extremely true to extremely untrue. BIS/ BAS scales are composed of 20 items grouped into four areas: the BIS area and three aspects of the BAS area. In the current study the BIS subscale (seven items, with a satisfactory reliability in the present sample: $\alpha=.72$ ) was of particular interest. Sample items are: If my child thinks something unpleasant is going to happen, he/she gets pretty worked up, and My child feels pretty worried when he/she knows someone is angry with him/her. 


\subsubsection{Self-Reported Arousal}

At the very beginning of the testing, prior to the stress manipulation, children were asked how they felt in the present moment. Specifically, they were asked if they were nervous, happy, sad, and/or anxious. If children responded to one of these questions with yes they were further asked if they were very nervous, happy, sad, or anxious, respectively, or only a little bit (format for obtaining self-reported feelings was adapted from research on preschool children's self-concept, Harter \& Pike, 1984). This allowed us to create categorical variables with three levels. Overall there was little variability in children's answers, as almost all children reported to be happy (only two responded with no), not being sad (only two responded with yes), and not being anxious (only three responded with yes). However, 50 children reported to be nervous ( 29 a little bit and 21 very) and 56 reported to be not nervous (cf. Table 1). At the very end of the testing (i.e., end of the second session) children were again asked how they felt in the present moment. Thirty-eight children reported to be nervous ( 23 a little bit and 15 very). Self-reported feelings of being nervous were included in the following analyses as a manipulation check (pre compared to post ratings).

\subsection{Statistical Analyses}

Overall, missingness was low and was due largely to child characteristics. Precisely, three children were sick at the second assessment, two children refused to complete each an individual task, two children did not know colours sufficiently well to complete the Stroop and the Backwards Colour Recall task, and for one test session an experimenter forgot to implement the experimental manipulation. As to outlier analysis, scores were excluded if they deviated \pm 3 standard deviations from the sample's mean; this concerned only four tasks of three children in total.

For all measures of EF, we created percent-correct responding scores in which the number of correct responses was divided by the total number of possible responses or the highest level of performance reached in our sample. For the following analyses the mean of these percent-correct responding scores was the dependent variable ( $E F$ Percent Correct). The EF Percent Correct score consisted for the majority of children out of four tasks (92.5\%), out of three tasks for four children, out of two tasks for one child, and for three children data from only one task were incorporated into the EF Percent Correct score.

To create high vs. low temperamental groups median splits for each temperamental variable were calculated: Inhibitory Control: median $=5[\mathrm{low} \leq 5, n=57$ and high $\geq 5.17, n=50]$, Attentional Focusing: median $=5.33$ $[$ low $\leq 5.33, n=55$ and high $\geq 5.4, n=52]$, Fear: median $=3.2[$ low $\leq 3.2, n=54$ and high $\geq 3.33, n=53]$, BIS: median $=4.57[$ low $\leq 4.57, n=55$ and $\operatorname{high} \geq 4.6, n=52]$.

Data were analyzed with SPSS 20 . To test our hypotheses concerning the differential impact of stress on EF, three-way analyses of variance (ANOVAs) were conducted: 2 (experimental vs. control group) x 2 (younger vs. older cohort) x 2 (high vs. low temperamental groups) with EF Percent Correct as outcome variable. Further, to test whether our stress manipulation raised children's self-reported arousal (i.e., manipulation check analysis) and thus, arousal can be considered as a mediator of the effects found, the following three-way ANOVA was conducted: 2 (experimental vs. control group) x 2 (younger vs. older cohort) x 2 (pre vs. post session) with session as a within-subject factor and self-reported arousal (with three levels) as outcome variable. Partial eta ${ }^{2}$ values $\left(\eta_{p}{ }^{2}\right)$ are reported as an estimation of the effect size.

\section{Results}

Table 1 presents the descriptive data for all measures incorporated in the present study and Table 2 shows zero-order correlations among the included variables as well as their correlations with age and gender. Inter-correlations of EF tasks were low to moderate which is a typical finding in children of this age group (with the exception of the correlation between the Stroop and the Backwards Color Recall task not reaching level of statistical significance). Furthermore, as expected, older children outperformed younger children (see Table 2); however, the effect of age was only marginally significant for the Stroop task. Unexpectedly, children's self-reported arousal was positively associated with age, indicating that significantly more 6-year-olds than 4-year-olds reported to be nervous. Furthermore, the older the children were the higher their BIS was rated by their parents. Girls outperformed boys in the Stroop and Go/no-go task whereas in the composite score of $E F$ Percent Correct no significant gender differences were found. Finally, girls were rated by their parents to have significantly higher Inhibitory Control and showing more Fear than boys. 
Table 1. Descriptive statistics

\begin{tabular}{|c|c|c|c|}
\hline & $N$ & $M(S D)$ & $\min -\max$ \\
\hline \multicolumn{4}{|l|}{ EF } \\
\hline Stroop (errors) & 104 & $1.72(1.5)$ & $0-6$ \\
\hline GoNoGo (Discrimination Index) & 101 & $.56(0.16)$ & $.11-.91$ \\
\hline Flanker (accuracy) & 106 & $.82(0.2)$ & $.25-1$ \\
\hline Backwards Color recall (trials) & 104 & $4.08(0.16)$ & $0-9$ \\
\hline EF Percent Correct (\%, mean of all tasks) & 107 & $63.46(15.62)$ & $21.01-88.98$ \\
\hline \multicolumn{4}{|l|}{ Temperament } \\
\hline CBQ Inhibitory Control & 107 & $4.94(1.07)$ & $2.5-7$ \\
\hline CBQ Attentional Focusing & 107 & $5.29(1.01)$ & $2.33-6.83$ \\
\hline CBQ Fear & 107 & $3.43(1.32)$ & $1-6$ \\
\hline BIS & 107 & $4.49(0.96)$ & $2.29-6.57$ \\
\hline \multicolumn{4}{|l|}{ Self-reported arousal } \\
\hline pre & 106 & $.67(0.79)$ & $0-2$ \\
\hline post & 102 & $.52(0.74)$ & $0-2$ \\
\hline
\end{tabular}

Notes. $\mathrm{EF}=$ Executive Functions. Discrimination Index $=$ Hits minus False Alarms. Temperament was rated on a 7-point Likert scale. Self-reported arousal: $0=$ no, $1=$ yes, a little bit, and $2=$ yes, very.

Table 2. Correlations among study variables (including gender and age)

\begin{tabular}{|c|c|c|c|c|c|c|c|c|c|c|c|c|c|}
\hline & 1 & 2 & 3 & 4 & 5 & 6 & 7 & 8 & 9 & 10 & 11 & Age & Gender \\
\hline 1. EF Percent Correct & -- & & & & & & & & & & & $.63 * * *$ & -.14 \\
\hline 2. Stroop & $-.60^{* * *}$ & -- & & & & & & & & & & $-.19^{+}$ & $.22^{*}$ \\
\hline 3. Flanker & $.77 * * *$ & $-.29^{* *}$ & -- & & & & & & & & & $.64 * * *$ & -.07 \\
\hline 4. Go/no-go & $.70 * * *$ & $-.25^{*}$ & $.48^{* * *}$ & -- & & & & & & & & $.45 * * *$ & $-.22^{*}$ \\
\hline $\begin{array}{l}\text { 5. Backwards Color } \\
\text { Recall }\end{array}$ & $.73 * *$ & -.08 & $.48^{* * *}$ & $.36 * * *$ & -- & & & & & & & $.53 * * *$ & .05 \\
\hline $\begin{array}{l}\text { 6. CBQ Inhibitory } \\
\text { Control }\end{array}$ & .12 & -.13 & .12 & .08 & .04 & -- & & & & & & .12 & $-.25^{* *}$ \\
\hline $\begin{array}{l}\text { 7. CBQ Attentional } \\
\text { Focusing }\end{array}$ & $.18^{+}$ & -.16 & .15 & .15 & .08 & $.60 * * *$ & -- & & & & & .11 & -.06 \\
\hline 8. CBQ Fear & .04 & -.03 & -.03 & $.20^{*}$ & .04 & $.23^{*}$ & .11 & -- & & & & .02 & $-.32^{* *}$ \\
\hline 9. BIS & .10 & .07 & .09 & .05 & .02 & .12 & .03 & $.25 * *$ & -- & & & $.24^{*}$ & -.09 \\
\hline $\begin{array}{l}\text { 10. Self-reported } \\
\text { arousal pre }\end{array}$ & .06 & -.06 & .09 & .10 & -.05 & .12 & .13 & -.03 & .09 & -- & & $.20^{*}$ & -.02 \\
\hline $\begin{array}{l}\text { 11. Self-reported } \\
\text { arousal post }\end{array}$ & -.02 & .08 & .08 & .13 & -.11 & -.09 & -.02 & -.02 & -.03 & $.50^{* * *}$ & -- & .05 & .07 \\
\hline 12. Stress manipulation & -.08 & .06 & -.11 & .01 & -.05 & -.06 & -.09 & .09 & .14 & -.04 & .03 & -.01 & .01 \\
\hline
\end{tabular}

Notes. $N=101-107 . \mathrm{EF}=$ Executive Functions. Stroop is reversely coded. Gender coded: $1=$ girls and $2=$ boys. Stress manipulation coded: control group $=1$ and experimental group $=2$.

${ }^{+} p \leq .06,{ }^{*} p<.05,{ }^{* *} p<.01, * * * p<.001$ (2-tailed). 


\subsection{Self-Reported Arousal}

A three-way ANOVA revealed a marginally significant main effect of age, $F(1,97)=3.3, p=.072, \eta_{\mathrm{p}}{ }^{2}=.03$, which was qualified by an age $\mathrm{x}$ session interaction, $F(1,97)=5.1, p<.05, \eta_{\mathrm{p}}{ }^{2}=.05$, indicating that 6 -year-olds reported to be more aroused than 4-year-olds but that difference was more pronounced in the pre reports $(M$ 6-year-olds $=.79, S E=.09$ vs. $\left.M_{4 \text {-year-olds }}=.35, S E=.14\right)$ compared to the post reports $\left(M_{\text {6-year-olds }}=.53, S E=.09\right.$ vs. $M_{4 \text {-year-olds }}=.45, S E=.13$ ) (cf. Figure 1). Contradictory to our hypothesis, the session $\mathrm{x}$ stress interaction did not reach level of statistical significance, $F(1,97)=1.6, p=.21$. However, on a descriptive level it can be seen that 4-year-olds in the experimental group reported to be more nervous in the second session, whereas in all the other groups arousal was lower in the second session.

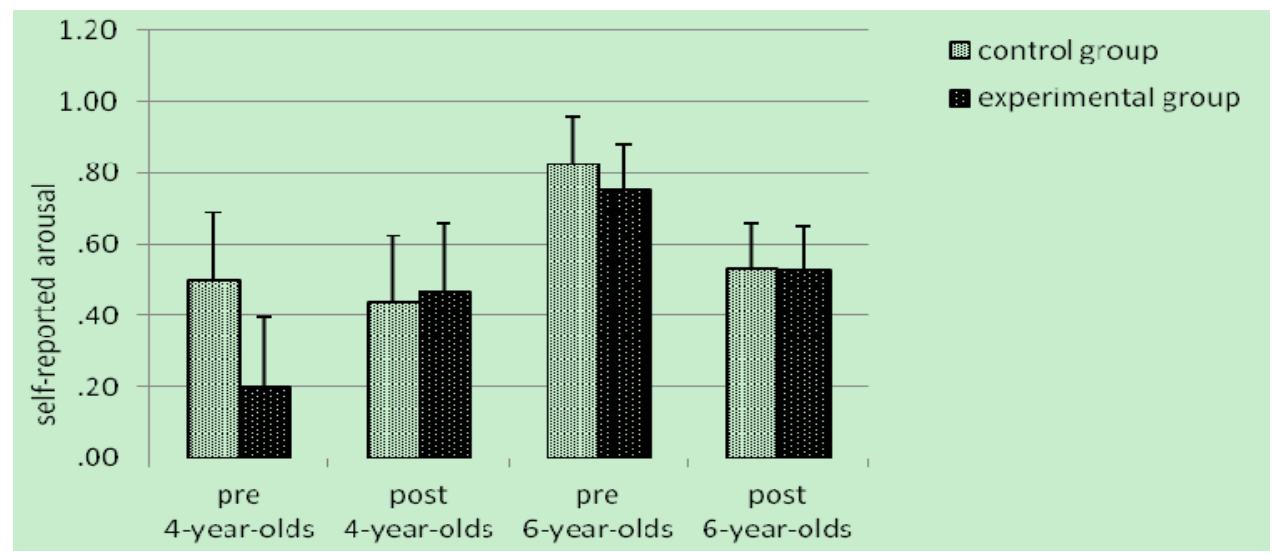

Figure 1. Effects of stress on self-reported arousal as a function of age and session

Description: The older cohort reported to be more aroused than the younger cohort but that difference was more pronounced in the first session compared to the second (2-way interaction, $p<.05, \eta_{p}{ }^{2}=.05$ ). Contradictory to our hypothesis, the session $\mathrm{x}$ stress interaction did not reach level of statistical significance $(p=.21)$. Displayed are estimated marginal means and standard errors.

In sum, self-reported arousal was not a significant mediator of stress effects on children's EF. Note that the study lacked of sufficient power to detect any significant effects even if they existed in reality (i.e., power statistics of 0.73 were not above the recommended value of 0.80 ).

\subsection{Self-Regulatory Aspects of Temperament: Inhibitory Control and Attentional Focusing}

\subsubsection{Inhibitory Control}

A three-way ANOVA revealed significant main effects of age, $F(1,99)=59.4, p<.001, \eta_{\mathrm{p}}{ }^{2}=.38$, and stress, $F(1,99)=4.8, p<.05, \eta_{\mathrm{p}}{ }^{2}=.05$, which were qualified by an age x stress interaction, $F(1,99)=6.8, p<.05, \eta_{\mathrm{p}}{ }^{2}$ $=.06$, a stress $\mathrm{x}$ Inhibitory Control interaction, $F(1,99)=7.4, p<.01, \eta_{\mathrm{p}}{ }^{2}=.07$, and finally, a significant three-way interaction, $F(1,99)=4.0, p<.05, \eta_{\mathrm{p}}{ }^{2}=.041^{1}$. Because main effects are influenced by interactions, we focused further post hoc analysis on the latter (cf. Figure 2). Specifically, stress affected the 4-year-olds negatively $\left(M_{\text {experimental group }}=-1.1, S E=.16\right.$ vs. $\left.M_{\text {control group }}=-0.38, S E=.19\right)$ whereas the 6-year-olds showed small positive effects under the stress condition ( $M_{\text {experimental group }}=0.49, S E=.12$ vs. $M_{\text {control group }}=0.42, S E$ $=.13)$. The three-way interaction indicated that only those 4-year-olds with high Inhibitory Control were negatively affected by the stress manipulation ( $M_{\text {IC high experimental group }}=-1.61, S E=.26$ and $M_{\text {IC high control group }}=$ $-0.12, S E=.32$ vs. $M_{I C}$ low experimental group $=-0.64, S E=.24$ and $\left.M_{\text {IC low control group }}=-0.64, S E=.21\right)$. Thus, contradictory to our hypothesis, children (i.e., 4-year-olds) with high Inhibitory Control showed a strong decline in their EF performance when stress was induced.

\subsubsection{Attentional Focusing}

A three-way ANOVA revealed again a significant main effect of age, $F(1,99)=55.2, p<.001, \eta_{\mathrm{p}}{ }^{2}=.36$, and only a marginally significant main effect of stress, $F(1,99)=3.5, p=.065, \eta_{\mathrm{p}}{ }^{2}=.03$. These main effects again were qualified by a significant age $\mathrm{x}$ stress interaction, $F(1,99)=6.1, p<.05, \eta_{\mathrm{p}}{ }^{2}=.06$, indicating that stress affected the 4-year-olds negatively $\left(M_{\text {experimental group }}=-1.1, S E=.20\right.$ vs. $\left.M_{\text {control group }}=-0.43, S E=.19\right)$ whereas the 6-year-olds were slightly positively affected ( $M_{\text {experimental group }}=0.47, S E=.12$ vs. $M_{\text {control group }}=0.38, S E$ 
$=.13)$. Thus, this result is similar to that found within the analyses of Inhibitory Control. Furthermore, there was a significant stress $\mathrm{x}$ Attentional Focusing interaction, $F(1,99)=4.1, p<.05, \eta_{\mathrm{p}}{ }^{2}=.04$, indicating that children were affected differently by stress depending on their level of Attentional Focusing (cf. Figure 3). Precisely, in the control group high Attentional Focusing children outperformed their peers with low Attentional Focusing $(M$ $A F$ high control group $=0.25, S E=.17$ vs. $M_{A F}$ low control group $\left.=-0.29, S E=.15\right)$, whereas in the experimental group differences between high and low Attentional Focusing children were smaller and in the opposite direction $\left(M_{A F}\right.$ high experimental group $=-0.38, S E=.18$ vs. $M_{A F}$ low experimental group $\left.=-0.27, S E=.13\right)$. Thus, contradictory to our hypothesis, children with high Attentional Focusing showed impaired EF performance when stress was induced. However, a closer look on the data (cf. Figure 3) makes it clear that 4-year-olds with low Attentional Focusing also showed a decline in their EF performance when stress was induced (although to a lesser extent than their peers with high Attentional Focusing), and only 6-year-olds with high Attentional Focusing seemed to benefit from the experimental manipulation. However, as the three-way interaction did not reach statistical significance, $F(1,99)=0.2, p=.64$, these later interpretations are merely based on a descriptive level and should be therefore considered with caution.

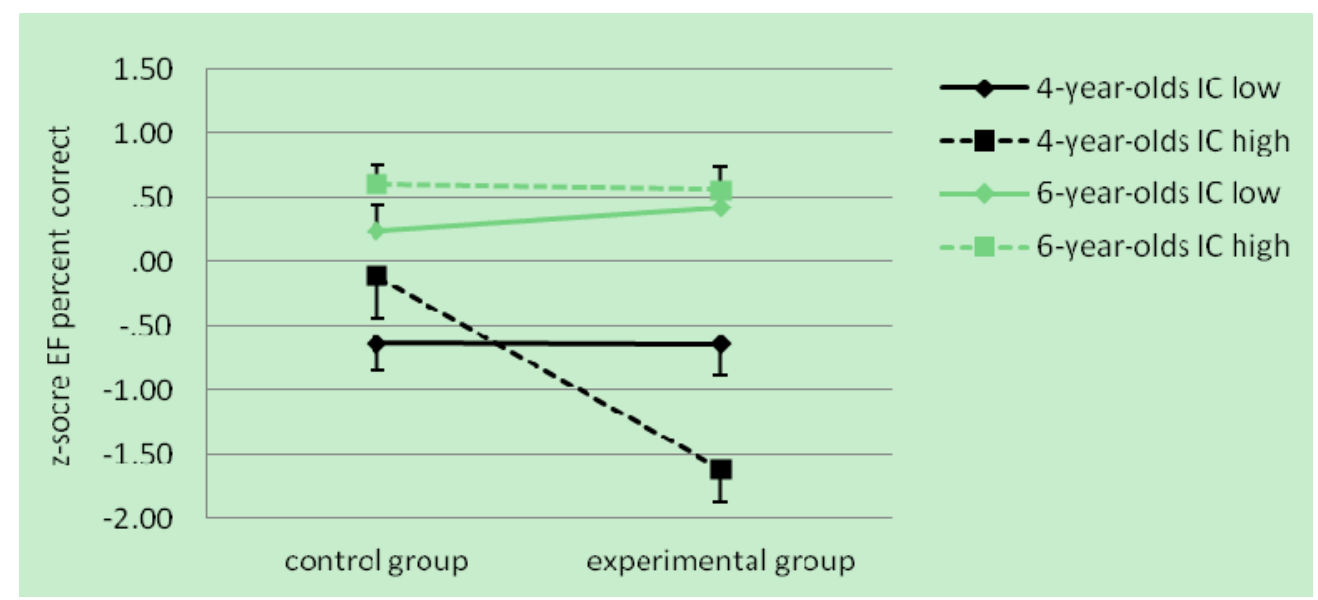

Figure 2. Effects of stress on EF as a function of age and Inhibitory Control (IC)

Description: Stress had a significant effect on EF, but only in the younger cohort and only in children with high Inhibitory Control (3-way interaction, $p<.05, \eta p^{2}=.04$ ). Displayed are estimated marginal means and standard errors.

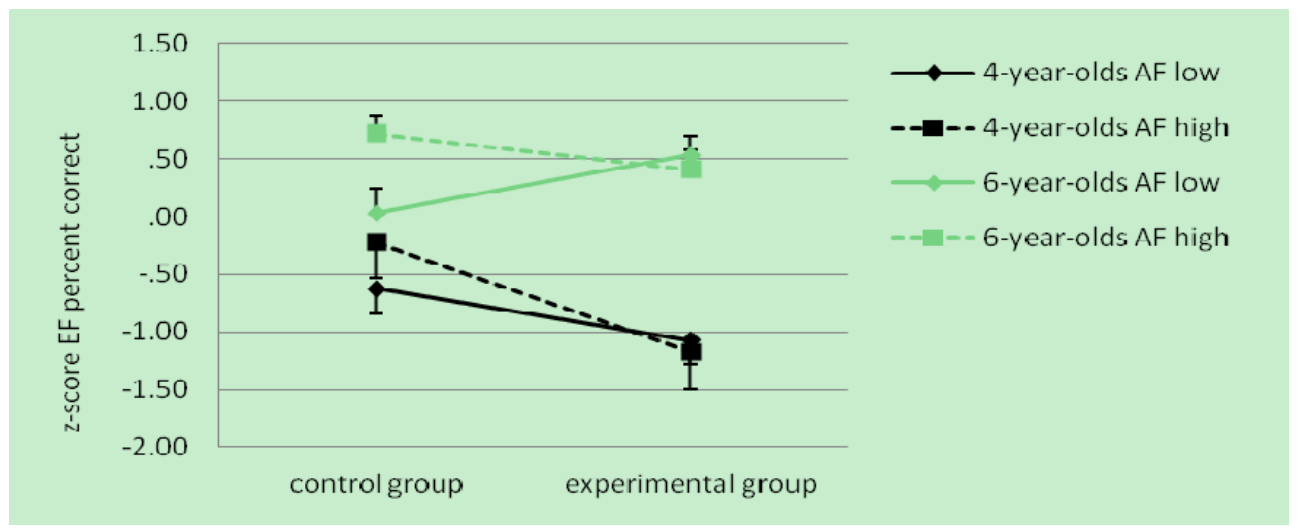

Figure 3. Effects of stress on EF as a function of age and Attentional Focus (AF)

Description: Stress had an effect on $\mathrm{EF}$, but only in the younger cohort (2-way interaction, $p<.05, \eta_{p}{ }^{2}=.06$ ). Moreover, stress significantly reduced the difference between high and low AF children (2-way interaction, $p$ $\left.<.05, \eta_{p}{ }^{2}=.04\right)$. Displayed are estimated marginal means and standard errors. 


\subsection{Emotional Reactivity Aspects of Temperament: Fear and BIS}

\subsubsection{Fear}

A three-way ANOVA revealed once more significant main effects of age, $F(1,99)=66.1, p<.001, \eta_{\mathrm{p}}{ }^{2}=.40$, and stress, $F(1,99)=4.2, p<.05, \eta_{\mathrm{p}}{ }^{2}=.04$, which were qualified by an age $\mathrm{x}$ stress interaction, $F(1,99)=4.1, p$ $<.05, \eta_{\mathrm{p}}{ }^{2}=.04^{2}$. Again, as in the previous analyses, stress only had a compromising effect on the 4-year-olds whereas 6 -year-olds were slightly positively affected by the experimental manipulation. Contradictory to our hypothesis, Fear, did not have any significant moderating effect on children's EF performance.

\subsubsection{BIS}

A three-way ANOVA revealed again a significant main effect of age, $F(1,99)=57.8, p<.001, \eta_{\mathrm{p}}{ }^{2}=.37$, and a marginally significant main effect of stress, $F(1,99)=3.3, p=.074, \eta_{\mathrm{p}}{ }^{2}=.03$, which were qualified by a marginally significant age $\mathrm{x}$ stress interaction, $F(1,99)=3.4, p=.067, \eta_{\mathrm{p}}{ }^{2}=.03$. Again, as in the previous analyses, stress only had a compromising effect on the 4-year-olds whereas 6-year-olds were slightly positively affected by the experimental manipulation. BIS, in contrast and contradictory to our hypothesis, did not have any significant effect on children's EF performance.

In sum, stress effects on children's EF performance were moderated by age. Whereas 4-year-olds were negatively affected by the stressor, 6-year-olds did not show any stress effects or were even slightly positively affected by the stressor. Furthermore, self-regulatory aspects of temperament moderated stress effects, whereas emotional reactivity aspects of temperament did not. More precisely, 4-year-olds high in Inhibitory Control showed strong declines in their EF performance when stress was induced as well as children with high Attentional Focusing. If any stress effects or interactions were found, effect sizes were small (i.e., $\eta_{p}{ }^{2}=.03$ to .07 , indicating that mere $3 \%$ to $7 \%$ of the variance in test performance was accounted for by the stress manipulation, whereas the stress $\mathrm{x}$ age and stress $\mathrm{x}$ temperament interactions generally covered slightly higher percentages of explained variance).

\section{Discussion}

We tested a core assumption of the bidirectional model of EF (Blair \& Ursache, 2011) indicating that EF is dependent on stress arousal. From a bottom-up perspective the performance on EF tasks is assumed to be curvilinearly related to arousal, with very high or low levels of arousal impairing EF. We found stress effects on young children's EF performance that are moderated by age and temperament: 4-year-olds with high Inhibitory Control and high Attentional Focusing were negatively affected by the stressor. However, it is unclear whether these effects were mediated by self-reported arousal. Our findings disconfirmed the hypotheses that adverse effects of the stressor are particularly high in children high on emotional reactivity aspects of temperament and low on self-regulatory aspects of temperament. Further, 6-year-olds did not show any stress effects. Possible explanations are offered to account for these findings.

\subsection{General and Age-Specific Stress Effect}

Regarding the first two hypotheses (i.e., "children who were exposed to the stressor have fewer correct responses on the EF tasks" and "stress effects are more pronounced in the younger cohort"), we argued from a developmental perspective that specific EF tasks would be more difficult for 4-year-olds compared to 6-year-olds. Significant age differences suggest that tasks were indeed more difficult for younger than older children and hence, younger children may have been more aroused while performing these tasks, possibly being more vulnerable to EF impairments under the stressful condition (i.e., the stress manipulation rose their arousal to levels that were no more conducive to EF). Contradictory to our hypothesis, however, 6-year-olds' EF performance was not or even slightly positively affected by the stress manipulation. This finding may be interpreted in several ways. In line with the argument of difficulty of task and in conjunction with the Yerkes-Dodson law, it may be that the 6-year-olds did not show any impaired EF performance in presence of the stress manipulation because the EF tasks were not that difficult for them and consequently their arousal was not that high. In other words, their EF performance was quite robust and therefore not that susceptible to manipulation - unlike the performance of the younger children.

Alternatively, the present stress manipulation itself was not effective for 6-year-olds. The present weak stress manipulation was designed to be similar to a naturally occurring stressor in preschool and early school children's life, in order to enhance the ecological validity of the findings (a claim that was raised by other researchers within the field e.g., Gilissen, Bakermans-Kranenburg, Ijzendoorn, \& Linting, 2008). Compared to the well-established Trier Social Stress Test for Children (Buske-Kirschbaum et al., 1997) our stress manipulation procedure was much shorter and less intense and can be therefore considered a weak social-evaluative threat. 
Against this background, it is noteworthy that we were still able to find effects for 4-year-olds. By 6-year-olds this stress manipulation does not appear to have effects, and therefore a stronger stress manipulation is warranted for children in that age range. Possibly, 6-year-olds did not perceive our stress manipulation as threatening as these children already attend regular schooling and are used to these kinds of social-evaluative situations in terms of exams (and possibly comparing their results in exams with the ones of their class mates). Our data even provide weak evidence that some of the 6-year-olds may benefit from such a social-evaluative situation. In terms of the Yerkes-Dodson law, 6-year-olds with low Attentional Focusing and low Inhibitory Control may become optimally aroused by these evaluative situations, and are then able to perform on the EF tasks at their optimal level. However, this is speculative at best and requires further investigation in future studies. Regarding the very small effect sizes, it is questionable, if these obviously small performance deficits or gains manifest in everyday life at all.

Interestingly and contradictory to our hypothesis, the stress manipulation did not affect children's self-reported arousal. Although the significant stress effects on the EF tasks suggest that the manipulation did work, findings from the self-report suggest otherwise. Similar to our findings, Ng and Lee (2010) failed to find a significant interaction between situational stress (evaluative task condition) and self-reported state test anxiety scores but they observed significant effects of the stress manipulation on task performance, as we did. One possibility is that the manipulation did not have a large effect on children's perception of their level of arousal (i.e., being nervous, experiencing high state test anxiety). Another possibility is that our measure may not have been reliable (cf. single item) and validity may have also been low (not established measure). However, with a larger sample, self-reported arousal may be identified as a significant mediator of stress effects because at a descriptive level our data suggest that the stress manipulation possibly affected those children (i.e., 4-year-olds) the most who reported to be nervous. Future research may benefit by including biological/ physiological measures (i.e., cortisol, heart rate) to test mechanisms of how stress affects EF performance on a biological level and comparing these mechanisms to psychological mediators. Moreover, it would be interesting to compare distinct naturally occurring stressors (i.e., social-evaluative threat vs. test anxiety vs. social exclusion) because different children may be stressed out by different stressors.

\subsection{Self-Regulatory and Emotional Reactivity Aspects of Temperament as Moderators}

Temperamental factors were shown to moderate stress effects although the pattern of results did not conform to our hypotheses (i.e., "children high on self-regulatory aspects of temperament are better at regulating the heightened arousal" whereas "children high on emotional reactivity aspects of temperament are at higher risk for inferior performance on the EF tasks under the stress condition"). Interestingly, children high on self-regulatory aspects of temperament did not continue to perform well on EF tasks when experiencing stress: 4-year-olds with high Inhibitory Control and high Attentional Focusing actually showed relatively strong declines under the stress condition. Possibly these children performed the EF tasks at their individual's maxim (being highly and well regulated in the control group), with our stress manipulation then leading to too high levels of arousal impairing their EF performance. In this context the control group can be seen as having experienced a positive environment as our research assistants were trained to praise children for their performance regardless of their actual performance (and regardless if they were in the control or experimental group). Thus, the nurturing setting of the control group (i.e., just experiencing the praise provided by the research assistant without the social-evaluative threat that was induced in the experimental group) possibly allowed more inhibited children (high on Inhibitory Control) to fully unfold their potential (i.e., to use their EF skills at their individual's maximum). This finding is reminiscent of recent research on vantage sensitivity (Pluess \& Belsky, 2013) where temperamental factors were identified as behavioral vantage-sensitivity factors, explaining inter-individual variability in response to positive experiences. Future research, however, may address and test these questions in a straightforward manner to draw firmer conclusions.

Questions still remain, however, regarding why emotional reactivity aspects of temperament did not show any effects. The most obvious interpretation of these unexpected results seems to be that parents' rating may not be a valid indicator of children's emotional reactivity - at least in this context. Alternatively, anxiety rather than Fear or BIS may be the crucial emotional component related to performance impairments. Research on test anxiety, or more precisely, math anxiety, has found negative effects of spatial anxiety on children's (Ramirez, Gunderson, Levine, \& Beilock, 2012) and adult's task performance (Ashcraft \& Kirk, 2001; Mattarella-Micke, Mateo, Kozak, Foster, \& Beilock, 2011). However, as one of the few studies on test anxiety including a situational stressor (cf. experimental stress manipulation), $\mathrm{Ng}$ and Lee (2010) failed to find a significant interaction between evaluative vs. non-evaluative task condition and trait test anxiety on children's performance. Importantly, in all these studies anxiety was assessed with self-report measures which may be a crucial feature. Future research may 
benefit from assessing emotional reactivity and anxiety or fear with distinct measures and comparing them to each other.

\subsection{Limitations and Conclusion}

Although, we interpreted our findings in terms of the relationship between EF and emotional arousal mirroring an inverted U-shape, with the upward part reflecting energizing effects of arousal whereas the downward part reflecting deteriorating effects of arousal on EF, our study faced several limitations. First, because our study lacked a measure of experienced task difficulty it is not clear if the 4-year-olds actually experienced the EF tasks as more difficult and, hence, were more aroused when solving these tasks than the 6-year-olds. The interaction of task difficulty and induced stress could therefore not be directly tested, but only inferred from age-performance interactions, which is problematic because EF performance plays a dual role (indirect indicator of experienced task difficulty and study outcome). Second, as mentioned above our measure of self-reported arousal was weak and also the study would have benefited if anxiety would have been assessed. Finally, conclusions are based on relatively low cell frequencies in the ANOVAs.

Despite these limitations, our data show that the theoretical framework of the bidirectional model of EF (Blair \& Ursache, 2011) is a promising venue to study stress effects on EF. Although our findings must be interpreted with caution because of the issues discussed above, it is an interesting starting point to not only gain insight into differential impacts of emotional arousal on children's EF but also more generally on how different contexts may affect children's EF. Future research may address limitations and weaknesses of the present study to contribute to a deeper understanding of how children are most efficiently supported to engage in successful self-regulation in early school contexts. Being optimally aroused seems to matter for engaging in successful self-regulation!

\section{Acknowledgements}

This research was supported by a postdoctoral fellowship from Swiss National Science Foundation (SNSF Grant No. PBBEP1_144852) to the first author. We would like to thank master students from University Bern for their assistance with recruitment and data collection, Sarah Loher for her help with eprime tasks, and especially the participating children, parents, and teachers, without whom this study would not have been possible.

\section{References}

Alexander, J. K., Hillier, A., Smith, R. M., Tivarus, M. E., \& Beversdorf, D. Q. (2007). Beta-adrenergic modulation of cognitive flexibility during stress. Journal of Cognitive Neuroscience, 19, 468-478. http://dx.doi.org/10.1162/jocn.2007.19.3.468

Archibald, S. J., \& Kerns, K. A. (1999). Identification and description of new tests of executive functioning in children. Child Neuropsychology, 5, 115-129. http://dx.doi.org/10.1076/chin.5.2.115.3167

Arnsten, A. F. T. (2009). Stress signalling pathways that impair prefrontal cortex structure and function. Nature Review Neuroscience, 10, 410-422. http://dx.doi.org/10.1038/nrn2648

Arnsten, A. F. T., \& Goldman-Rakic, P. S. (1998). Noise stress impairs prefrontal cortical cognitive function in monkeys: Evidence for a hyperdopaminergic mechanism. Archives of General Psychiatry, 55, 362-368. http://dx.doi.org/10.1001/archpsyc.55.4.362

Ashcraft, M. H., \& Kirk, E. P. (2001). The relationships among working memory, math anxiety and performance. Journal of Experimental Psychology: General, 130, 224-237. http://dx.doi.org/10.1037/0096-3445.130.2.224

Atkinson, J. W. (1957). Motivational determinants of risktaking behavior. Psychological Review, 64, 359-372. http://dx.doi.org/10.1037/h0043445

Baumeister, R. F., Vohs, K. D., \& Tice, D. M. (2007). The strength model of self-control. Current Directions in Psychological Science, 16, 351-355. http://dx.doi.org/10.1111/j.1467-8721.2007.00534.x

Best, J. R., \& Miller, P. H. (2010). A developmental perspective on executive function. Child Development, 81, 1641-1660. http://dx.doi.org/10.1111/j.1467-8624.2010.01499.x

Blair, C. (2002). School readiness: Integrating cognition and emotion in a neurobiological conceptualization of children's functioning at school entry. American Psychologist, 57, 111-127. http://dx.doi.org/10.1037/0003-066X.57.2.111 
Blair, C. (2003). Behavioral inhibition and behavioral activation in young children: Relations with self-regulation and adaptation to preschool in children attending Head Start. Developmental Psychobiology, 42, 301-311. http://dx.doi.org/10.1002/dev.10103

Blair, C., \& Dennis, T. (2010). An optimal balance: The integration of emotion and cognition in context. In S. D. Calkins, \& M. A. Bell (Eds.), Child development at the intersection of emotion and cognition (pp. 17-35). Washington, DC: American Psychological Associoation. http://dx.doi.org/10.1037/12059-002

Blair, C., \& Ursache, A. (2011). A bidirectional model of executive functions and self-regulation. In K. D. Vohs, \& R. F. Baumeister (Eds.), Handbook of self-regulation: Research, theory, and applications (2nd ed., pp. 300-320). New York: Guilford Press.

Buske-Kirschbaum, A., Jobst, S., Wustmans, A., Kirschbaum, C., Rauh, W., \& Hellhammer, D. (1997). Attenuated free cortisol response to psychosocial stress in children with atopic dermatitis. Psychosomatic Medicine, 59, 419-426.

Buske-Kirschbaum, A., von Auer, K., Krieger, S., Weis, S., Rauh, W., \& Hellhammer, D. (2003). Blunted cortisol responses to psychosocial stress in asthmatic children: A general feature of atopic disease? Psychosomatic Medicine, 65, 806-810. http://dx.doi.org/10.1097/01.PSY.0000095916.25975.4F

Carver, C. S., \& White, T. L. (1994). Behavioral inhibition, behavioral activation, and affective responses to impending reward and punishment: The BIS/BAS scales. Journal of Personality \& Social Psychology, 67, 319-333. http://dx.doi.org/10.1037/0022-3514.67.2.319

Cragg, L., \& Nation, K. (2008). Go or no-go? Developmental improvements in the efficiency of response $\begin{array}{lllll}\text { inhibition in mid-childhood. Developmental } & \text { Science, } & 11(6), & 819-827 .\end{array}$ http://dx.doi.org/10.1111/j.1467-7687.2008.00730.x

Dickerson, S. S., \& Kemeny, M. E. (2004). Acute stressors and cortisol responses: A theoretical integration and synthesis of laboratory research. Psychological Bulletin, 130, 355-391. http://dx.doi.org/10.1037/0033-2909.130.3.355

Eriksen, B. A., \& Eriksen, C. W. (1974). Effects of noise letters upon the identification of a target letter in a nonsearch task. Perception \& Psychophysics, 16, 143-149. http://dx.doi.org/10.3758/BF03203267

Gilissen, R., Bakermans-Kranenburg, M. J., Ijzendoorn, M. H., \& Linting, M. (2008). Electrodermal reactivity during the Trier Social Stress Test for Children: Interaction between the serotonin transporter polymorphism and children's attachment representation. Developmental Psychobiology, 50, 615-625. http://dx.doi.org/10.1002/dev.20314

Gray, J. A. (1982). The neuropsychology of anxiety: An inquiry into the functions of the septo-hippocampal system. Oxford: Oxford University Press.

Gray, J. R. (2004). Integration of emotion and cognitive control. Current Directions in Psychological Science, 13, 46-48. http://dx.doi.org/10.1111/j.0963-7214.2004.00272.x

Gunnar, M. R., Talge, N. M., \& Herrera, A. (2009). Stressor paradigms in developmental studies: What does and does not work to produce mean increases in salivary cortisol. Psychoneuroendocrinology, 34, 953-967. http://dx.doi.org/10.1016/j.psyneuen.2009.02.010

Harter, S., \& Pike, R. (1984). The pictorial scale of Perceived Competence and Social Acceptance for Young Children. Child Development, 55, 1969-1982. http://dx.doi.org/10.2307/1129772

Lupien, S. J., Gillin, C. J., \& Hauger, R. L. (1999). Working memory is more sensitive than declarative memory to the acute effects of corticosteroids: A dose-response study in humans. Behavioral Neuroscience, 113, 420-430. http://dx.doi.org/10.1037/0735-7044.113.3.420

Lupien, S. J., Maheu, F., Tu, M., Fiocco, A., \& Schramek, T. E. (2007). The effects of stress and stress hormones on human cognition: Implications for the field of brain and cognition. Brain and Cognition, 65, 209-237. http://dx.doi.org/10.1016/j.bandc.2007.02.007

Mattarella-Micke, A., Mateo, J., Kozak, M. N., Foster, K., \& Beilock, S. L. (2011). Choke or thrive? The relation between salivary cortisol and math performance depends on individual differences in working memory and math-anxiety. Emotion, 11, 1000-1005. http://dx.doi.org/10.1037/a0023224

Miller, E. K., \& Cohen, J. D. (2001). An integrative theory of prefrontal cortex function. Annual Review of Neuroscience, 24, 167-202. http://dx.doi.org/10.1146/annurev.neuro.24.1.167 
Miyake, A., Friedman, N. P., Emerson, M. J., Witzki, A. H., \& Howerter, A. (2000). The unity and diversity of executive functions and their contributions to complex "frontal lobe" tasks: A latent variable analysis. Cognitive Psychology, 41, 49-100. http://dx.doi.org/10.1006/cogp.1999.0734

Ng, E., \& Lee, K. (2010). Children's task performance under stress and non-stress conditions: A test of the processing efficiency theory. Cognition and Emotion, 24, 1229-1238. http://dx.doi.org/10.1080/02699930903172328

Ochsner, K. N., \& Gross, J. J. (2005). The cognitive control of emotion. Trends in Cognitive Sciences, 9, 242-249. http://dx.doi.org/10.1016/j.tics.2005.03.010

Pluess, M., \& Belsky, J. (2013). Vantage sensitivity: Individual differences in response to positive experiences. Psychological Bulletin, 139, 901-916. http://dx.doi.org/10.1037/a0030196

Ramirez, G., Gunderson, E. A., Levine, S. C., \& Beilock, S. L. (2012). Spatial anxiety relates to spatial abilities as a function of working memory in children. The Quarterly Journal of Experimental Psychology, 65, 474-487. http://dx.doi.org/10.1080/17470218.2011.616214

Raver, C. (2002). Emotions matter: Making the case for the role of young children's emotional development for early school readiness. Society for Research in Child Development Social Policy Report, 16, 1-19.

Roebers, C. M., Schmid, C., \& Roderer, T. (2010). Encoding strategies in primary school children: Insights from an eye-tracking approach and the role of individual differences in attentional control. The Journal of Genetic Psychology, 171, 1-21. http://dx.doi.org/10.1080/00221320903300361

Rothbart, M. K., Ahadi, S. A., Hershey, K. L., \& Fisher, P. (2001). Investigations of temperament at three to seven years: The Children's Behavior Questionnaire. Child Development, 72, 1394-1408. http://dx.doi.org/10.1111/1467-8624.00355

Rothbart, M. K., \& Bates, J. E. (2006). Temperament. In N. Eisenberg (Ed.), Handbook of child psychology: Social, emotional, and personality development (6th ed., Vol. 3, pp. 99-166). New York: Wiley.

Röthlisberger, M., Neuenschwander, R., Michel, E., \& Roebers, C. M. (2010). Exekutive Funktionen: Zugrundeliegende kognitive Prozesse und deren Korrelate bei Kindern im späten Vorschulalter [Executive function and their correlates in late preschool children]. Zeitschrift für Entwicklungspsychologie und Pädagogische Psychologie, 42, 99-110. http://dx.doi.org/10.1026/0049-8637/a000010

Schmid, C., Zoelch, C., \& Roebers, C. M. (2008). Das Arbeitsgedächtnis von 4-bis 5-jährigen Kindern: Theoretische und empirische Analyse seiner Funktionen [Working memory in 4- to 5-yr-olds: Theoretical and empirical analyses of its functions]. Zeitschrift für Entwicklungspsychologie und Pädagogische Psychologie, 1, 2-12. http://dx.doi.org/10.1026/0049-8637.40.1.2

Strelau, J. (1995). Temperament and stress: Temperament as a moderator of stressors, emotional states, coping, and costs. In C. D. Spielberger, \& I. G. Sarason (Eds.), Stress and emotion: Anxiety, anger, and curiosity (Vol. 15, pp. 215-254). Washington, DC: Hemisphere.

Strobel, A., Beauducel, A., Debener, S., \& Brocke, B. (2001). Eine deutschsprachige Version des BIS/BAS-Fragebogens von Carver und White [A German version of Carver and White's BIS/BAS questionnaire]. Zeitschrift fuer Differentielle und Diagnostische Psychologie, 22, 216-227. http://dx.doi.org/10.1024//0170-1789.22.3.216

Wiebe, S. A., Sheffield, T. D., \& Espy, K. A. (2012). Separating the fish from the sharks: A longitudinal study of preschool response inhibition. Child Development, 83, 1245-1261. http://dx.doi.org/10.1111/j.1467-8624.2012.01765.x

Yerkes, R. M., \& Dodson, J. D. (1908). The relation of strength of stimulus to rapidity of habit formation. Journal of Comparative Neurology and Psychology, 18, 459-482. http://dx.doi.org/10.1002/cne.920180503

\section{Notes}

Note 1. As gender differences were found for Inhibitory Control, additional analyses were run. Note that results remained essentially the same when gender was included as a covariate in the ANOVA.

Note 2. As gender differences were found for Fear, additional analyses were run. Note that results remained essentially the same when gender was included as a covariate in the ANOVA. 


\section{Copyrights}

Copyright for this article is retained by the author(s), with first publication rights granted to the journal.

This is an open-access article distributed under the terms and conditions of the Creative Commons Attribution license (http://creativecommons.org/licenses/by/3.0/). 